\title{
O ESTRANHO, O ESTRANHAMENTO E O ESTRANGEIRO EM MONIQUE PROULX E CLARICE LISPECTOR ${ }^{*}$
}

\author{
Haydée Ribeiro Coelho**
}

\begin{abstract}
Resumo: Esse texto aborda o estranbo, o estranbamento e o estrangeiro a partir de alguns contos da literatura do Québec (Les aurores montréales, de Monique Proulx) $e$ de outras narrativas, de Clarice Lispector. Para desenvolver o tema, serão focalizados: o insulamento feminino e a descoberta do "eu"; a adolescência e a experiência do estranbo e, finalmente, o olhar do estrangeiro e o sentimento de ser estrangeiro/ estrangeira.
\end{abstract}

Quando se aborda a questão do estranho e do estranhamento, é impossível não fazer referência ao texto "O estranho". No decorrer de seu estudo, Freud mostra como o estranho está relacionado ao que é assustador, ao que provoca medo e terror (FREUD, 1969: 276); ao que causa "incerteza intelectual"(FREUD, 1969: 277); e ao complexo de castração (FREUD, 1969: 304). Destaca ainda a posição de Shelling, para quem "Unheimlich" (o estranho) "é tudo o que deveria ter permanecido secreto e oculto mas veio à luz" (FREUD, 1969: 282). "Heimlich" (familiar,

\footnotetext{
- Recebido para publicação em 15 de dezembro de 2004.

" Professora da Faculdade de Letras/UFMG.
} 
amistoso) constitui uma palavra na direção da ambivalência (FREUD, 1969: 283).

Freud afirma:

O escritor imaginativo tem, entre muitas outras, a liberdade de poder escolher o seu mundo de representação, de modo que este possa ou coincidir com as realidades que nos são familiares, ou afastar-se delas o quanto quiser. (FREUD, 1969: 310)

O estranho suscita o enfoque do estrangeiro. Em 1988, Julia Kristeva publica Etrangers à nous-mêmes. Traduzido no Brasil com o título Estrangeiros para nós mesmos, desenvolve, no primeiro capítulo, o tema do estrangeiro sob a forma de tocata e fuga, combinando, assim, uma livre movimentação pelo tema, forma polifônica e estilo contrapontístico. Em uma das modulações sobre o estrángeiro, nessa parte introdutória, Julia Kristeva, ao dedicar-se ao "caso Mersault", mostra o exílio interior do personagem de Camus, seu desenraizamento e sua "inquietante esranheza" (KRISTEVA, 1994: 33).

O livro de Julia Kristeva possibilita múltiplas abordagens. Estendendo-se, por exemplo, a questão do estrangeiro para o tema da viagem, pode-se dizer que esse se desdobra no estudo do exílio e da migração. Em Exílio: entre raizes e radares, que tem como centro o exílio brasileiro de 1964 a 1979, Denise Rollemberg, no âmbito da História, também dialoga, em vários momentos, com o texto de Julia Kristeva. Essa breve apresentação aponta para a complexidade do tema e a possibilidade de sua ampliação nos vários campos do saber.

$\mathrm{O}$ estranho, o estranhamento e o estrangeiro nos textos aqui focalizados decorrem de situaçōes do cotidiano urbano que se apresentam em alguns contos de Les aurores montréales 
(1999), de Monique Proulx e em narrativas de Clarice Lispector. $O$ insulamento feminino e a descoberta do "eu", a infância, a adolescência e a experiência do estranho, o olhar do estrangeiro sobre Montreal e o estrangeiro em $A$ bora da estrela delimitam o campo comparativo desse estudo.

O livro, de Monique Proulx, compõe-se de vinte e sete contos. Apresenta uma variedade sócio-cultural e lingüística decorrente do multiculturalismo, do bilingüismo e da inserção do inglês na língua francesa do Canadá. Todos esses aspectos podem ser vistos no conto metalingüístico que tem o mesmo nome do livro. Grande parte das narrativas da escritora canadense ocorre em Montreal.

A propósito do conto mencionado, Marie Cusson, com base na noção de jogo, tal como é concebida por Hans-Georg Gadamer, mostra que a escritura da cidade é "un jeu de combat" (CUSSON, 2002: 83) do qual Laurel, protagonista e futuro escritor, participa. Por meio dele e de outros personagens, Monique Proulx olha a cidade e focaliza sua estranheza, captando os desejos, as frustrações e as angústias dos seus habitantes. A respeito do título do livro, saliente-se o fragmento destacado do conto "Les aurores montréales":

Tout à coup, le titre de son livre lui apparaît, fulgurant sur la page blanche. Les Aurores montréales. Son livre s'appellera Les Aurores montréales, parce que s'entendil commenter, une cigarette aux lèvres, lui qui ne fume pas mais qui devra fumer un jour s'il veut dégager une image de force et de nonchalance, parce que Montréal est une ville qui n'arrête pas de changer - les journalistes notent frénétiquement tout ce qu'il dit pendant qu'il tire avec virilité sur sa cigarette -, est une ville qui additionne tellement les nouveaux visages que l'on perd toujours celui que l'on croyait enfin connaître- une 
journaliste particulièrement jolie lui adresse un sourire extatique et autre lui remet en catimini son numéro de téléphone.Son folles de lui. (PROULX, 1999: 163-164)

\section{O insulamento feminino e a descoberta do "eu"}

No conto "Madame Bovary", da escritora canadense, a protagonista lia, diariamente, uma crônica "avec un sourire souvent, et parfois avec une peine étrange qui s'incrustait dans sa poitrine" (PROULX, 1999: 125) que lhe possibilitava um caminho secreto, desvelador de seu cotidiano mesquinho. Sob o pseudônimo de Diana, a leitora, a quem me refiro, se identificando com a matéria narrada e com o autor dos textos, demonstra vontade de recebêlo em sua casa. Depois desse encontro inusitado, aparece publicada uma reportagem em que a Diana da vida real reconhece que foi objeto de uma das crônicas, sendo comparada à "madame" Bovary.

Após a leitura do livro de Flaubert, a personagem do conto, diferentemente daquela da ficção do autor francês, decide "vivre interminablement, même petrifiée, même creuse, en imaginant que l'arsenic avait ce goût douceâtre, innofensif, ce goût de larmes et de café noir". (PROULX, 1999: 138). Sob a perspectiva apresentada, o estranhamento pode ser compreendido pelo menos em dois níveis. O primeiro se refere ao estranhamento da personagem e o segundo decorre do questionamento do sistema literário francês em relação à literatura do Québec no contexto do século XX.

No conto "Amor" (Laços de família), já tăo conhecido do público brasileiro e focalizado por Nádia Battella Gotlib ${ }^{1}$, Ana vive o "estranho" pela visão que tem de um homem parado no

${ }^{1}$ GOTLIB, 1985 , p. 53-54. 
ponto: um cego que "mastigava goma na escuridão. Sem sofrimento, com os olhos abertos" (LISPECTOR, 1974: 20). O olhar de Ana sobre o cego rompe o ritmo ordenado do cotidiano. $O$ bonde, onde estava Ana, se torna "um fio partido" (LISPECTOR, 1974: 21). Sua sacola de compras, tecida de tricô de forma "tão íntima", depois que ela vê o cego, se mostra áspera pelas "gemas amarelas e viscosas" que caíram sobre ela. O mundo, vivenciado como "mal estar", recomeçava ao redor da personagem como "uma estranha música" (LISPECTOR, 1974:21), provocando-lhe uma "náusea doce". As sensações "goût douceâtre" e a "náusea doce", depreendidas dos contos já mencionados, suscitam a abordagem do ser estrangeiro em um contexto familiar, como se pode observar em "Fucking Bourgeois" (Monique Proulx) e "Feliz Aniversário" (Laços de família, de Clarice Lispector).

O título "Fucking Bourgeois" decorre de uma micro-narrativa, presente no interior do conto. Diz respeito a "un petit homme à lunettes épaisses, qui tient en laisse un chien noir et patient, et qui marche au milieu de la rue en lançant 'fucking bourgeois' a des adversaires invisibles". (PROULX, 1999: 213)

O texto trata de uma reunião social de que participam dois casais: Lili e Jean Eudes e, ainda, Thomas e Claire, encarregada de preparar a refeição para todos. Ela é escritora e, várias vezes, o marido Thomas e os amigos brindam sua perfeição que se manifesta em seus dotes culinários e nos seus escritos.

O conto, bem extenso, urdido com base no diálogo entre os comensais, evidencia a preocupação social dos personagens. Thomas, por exemplo, faz comentários sobre o "qui pèse sur l'humanité", como na afirmação:

“(...) Des gens s'entre-tuent partout pour des histoires de dieux et de clôtures, des enfants fument du crack au lieu de jouer au ballon prisonnier, des hommes abattent 
des femmes qui ont rompu leur laisse. Et au cour de notre chez-nous si civilisé, derrière la Place des Arts, il y a un être humain qui couche dehors à vingt-cinq degrés sous zéro." (PROULX, 1999: 200)

Thomas, por esse discurso, repele a desagregação social e o infame. No entanto, é ele quem desestabiliza o universo de Claire que achava que a vida poderia ser "bonne et sucré". Isso ocorre quando Claire, gentilmente, na noite gelada do jantar, vai buscar, em seu carro, trufas, para os amigos.

Do lado de fora de sua casa, ela olha pela janela e vê Thomas (seu marido) e Lili (sua amiga) se beijando. Nesse instante, Claire vive o estranho no mundo que lhe parecia tão solidário e familiar, como é possível observar:

"La scène est étonnante, la situation dramatique fabuleuse, des mots veulent se faufiler en moi pour forger une histoire plus réelle que la réalité, mais presque tout de suit arrive la douleur qui terrasse les mots, et les mots s'en vont, je n'ai plus de mots, je n'ai plus rien." (PROULX, 1999: 218)

Em "Feliz aniversário", de Clarice Lispector, o estranho se institui pela maneira como a personagem feminina, durante a comemoração de seus oitenta e nove anos, vê sua própria família. Nessa festa, na sala de visita, a distribuição espacial da família ocorre em consonância com as diferenças sociais.

A aniversariante vê os filhos como "ratos". Sua voz, até um determinado momento abafada, se mostra forte, como no protesto: “- Que vovozinha que nada!" (LISPECTOR, 1974: 68). Para ela, a festa era hostil, apesar de os filhos tentarem fazê-la de maneira familiar. 


\section{A infância, a adolescência e a experiência do estranho}

Além do personagem Laurel, protagonista e adolescente, experimentar o estranho e ser estrangeiro em Montreal (no conto "Les aurores montréales"), outras situações envolvendo a adolescência e o estranho aparecem na obra de Monique Proulx.

Em "Le Passage", o estranhamento, relacionado à adolescência, se mostra à protagonista quando ela vê o reflexo de sua imagem projetada no estanho de uma lâmpada:

"Gaby observa son reflet dans l'étain de la lampe: une tête sauvage et noire corsaire, avec, au front cette mèche provocante qu'elle avait conservé au delà de la mode punk, mais surtout une expression dans le visage qu'elle ne se connaissait pas, rageuse à force d'être passionnée!" (PROULX, 1999: 16)

A inquietude da personagem se traduz na busca de um lugar que não esteja associado ao anonimato e à mediocridade:

“(...) Et si l'univers, clos comme une pomme, ne lui faisait pas de place, jamais, nulle part? Et si elle n'était q'une parmi tant d'autres, naïve et née trop tard, condamnée au tarissement irrémédiable de ses dons, à l'anonyme médiocrité? (PROULX, 1999: 21)"

Joana, a protagonista de Perto do coração selvagem, investese contra a banalidade do cotidiano. Pelo imaginário, diverte-se com papelóes e cria poesia. A respeito desse primeiro romance de Clarice Lispector e seu processo criativo, Nádia Battella Gotlib comenta: 
"É logo no primeiro capítulo desse primeiro romance que se desenha uma poética do narrar. Capítulo que é mesmo o primordial, cena de origem de toda uma produção romanesca, intitula-se, muito a propósito, "O Pai", quando a criança, ociosa e só, brinca de "que-éque-eu-faço". Inventa. Entre os ruídos da máquina de escrever do pai - "tac-tac-tac" -, o silêncio arrastandose "zzzzzz" - e o guarda-roupa que dizia "roupa-roupa", neste mundo de sensações fortes e insólitas, a meninapoeta já percebe o mundo vital destinado a morte das "galinhas-que-não-sabiam-que-iam morrer" e que traduz em versos também insólitos como este: "As galinhas que estão no quintal já comeram duas minhocas mạs eu não vi." (GOTLIB, 1995: 169)

A experiência criadora, que dribla o quotidiano, aparece também em "Os desastres de Sofia", conto paradigmático da obra de Clarice Lispector. Nesse texto, a autora brasileira, valendo-se de Sofia, dessacraliza o saber instituído. A invenção de uma história pela protagonista, com base naquela contada pelo seu professor, não só transgride a autoridade como também institui uma poética questionadora e crítica. No conto "L'enfance de l'art", de Monique Proulx, o estranhamento surge da relação entre leitor e a matéria narrada. $O$ desejo infanto-juvenil e a brutalidade sexual geram o estranhamento expresso sob a forma de náusea:

"Cinq heures vingt. Le conducteur éjacule dans la bouche de Marie. Cela dure trois secondes. Marie pense à du lait pur et froid, à du cream soda, aux milk-shakes à la vanille mousseux de sa petite enfance, elle pense à autre chose, mais ce n'est pas facile." (PROULX, 1999: 101) 
O ollhar do estrangeiro sobre Montreal e o estrangeiro em A bora da estrela

Monique Proulx trabalha, em muitos contos, o olhar do estrangeiro sobre Montreal. Três desses textos são dedicados aos chamados escritores migrantes: "Jaune et Blanc", "Rose et Blanc" e "Noir et Blanc".

A autora canadense abre seu livro com o conto "Gris et Blanc" que é uma carta escrita por um migrante de Costa Rica a "Manu", possível leitor e habitante de Puerto Quepos ( Je t' écris Manu, même si tu ne sais pás lire"). A vida em Montréal é descrita como "nordique et extrêmement civilisé". A paisagem cinzenta, no entanto, é o que mais the incomoda. Sua mãe é empregada de um "magasin", comparado a uma grande cidade. Essa imagem também reaparece em "Jaune et Blanc", texto dedicado a Ying Chen, escritora canadense de origem chinesa. $\mathrm{Na}$ carta/conto da neta chinesa, escrita para sua avó, há uma mescla entre o ficcional e o real, impulsionando uma reflexão sobre o relacionamento entre a literatura e a migração.

Montreal, vista como um "magasin", é múltipla e abundante, "semblable a un archipel aux îlots surpeplées, dont les foules denses sont formés d'objets plutôt que d'être vivants, un magasin au nom étrange qui ne fournit aucun indice de son contenu: 'Canadian Tire'." (PROULX, 1999: 53)

A estranheza das línguas, observada pela remetente da carta, resulta não somente do sistema lingüístico, mas sobretudo da cultura. Assim, o mundo dos objetos e a disposição dos mesmos no "magasin" obedecem ao critério cultural, distinto para o migrante. Quando a personagem, de origem chinesa, vê "pás", pensa em encontrar, possivelmente, junto das mesmas, "de la broche ou du bois", para suas flores. Essa expectativa, no entanto, é frustrada. Vejam-se os trechos: 
“(...) Soudain, encore plus loin, j'ai vu des pelles. Des pelles, grand-mère, des soeurs familières de celles que nos paysans enfonçaient dans la terre de l'autre côté du Huangpu, et je me suis precipitée vers elles, car ou il y avait des pelles il y aurait peut-être de la broche ou du bois pour mes fleurs, pour mes pauvres dahlias que le flot des choses sans nom commençait à entraîner dans l'oubli." (PROULX, 1999: 55)

"Je n'ai pás trouvé de broche ou de bois, mais j'ai trouvé quarantes-neuf sortes de pelles, et dix-huit sortes d'un Gros outil appelé Wed Eater, une chose démesurée enveloppé dans du plastique et perchée au-dessus des allées comme um roi aux pouvoirs obscurs." (PROULX, 1999: 55)

Nesse mesmo contexto, a remetente chinesa se vê como um arbusto "transplantado na América do Norte". Sua solidão se traduz, de forma paradoxal, pela expressão "dolorosa" e "magnífica liberdade".

Ying Chen escreveu vários romances como: La mémoire de l'eau (1922); Les lettres chinoises (1993) e L'Ingratitude (1995). Se se compara a fala da protagonista de L'Ingratitude com a da migrante chinesa em Blanc et Jaune, vê-se que há uma diferença em relação à maneira de focalizar a China. No romance, em evidência, a personagem feminina maquina a própria morte e não acha que encontrou "son milieu" como a migrante chinesa de "Blanc et Jaune". Ainda em L' Ingratitude, o espaço chinês surge apenas como referência, não havendo uma justaposição de espaços, como se pode observar em outro romance de migração e de exílio, como é o caso do romance de Sergio Kokis, brasileiro, naturalizado canadense, cuja obra (Le pavillon des miroirs) foi traduzida no Brasil como $A$ casa dos espelhos. 
Em "Jaune et Blanc", a autora canadense, ao dialogar com Ying Chen, nos remete à Yan-Zi, protagonista de L'Ingratitude: "Je veux te rassurer sur le sort de ta petite, avant que Seigneur Nilou ne t'attire tout à fait dans son royaume." (PROULX, 1999: 57). No romance $L^{\prime}$ Ingratitude, o Senhor Nilou defende a permanência dos valores da cultura e tradição chinesas.

Em "Noir et Blanc", texto dedicado a Dany Laferrière, de origem haitiana, o narrador/emissor, considerando que o texto é um conto e, ao mesmo tempo, carta, revela ao seu interlocutor os preconceitos raciais vividos pela família no Canadá. Mesmo assim, faz o convite ao "remetente" a ir para Montreal, tendo em vista que "notre Dany" "est un roi à Montréal".

"Rose et Blanc", dedicado a Marco Micone, autor de Le Figuier enchanté, constitui-se como carta de amor a Ugo Lugorio, migrante italiano. Trata-se de um texto que utiliza uma retórica que aproxima o emissor feminino (quebequense, órfão do passado) do imigrante italiano. Essa orfandade do passado instaura o sentimento de ser estrangeiro até mesmo no território em que o próprio sujeito construiu parte de sua história.

Considerando que esses vários contos instituem um diálogo profundo com as obras dos autores migrantes, o estudo das narrativas de Monique Proulx merece maior aprofundamento, matéria a ser tratada em estudos posteriores.

A condição de estrangeira, em seu próprio território, também se faz presente em $A$ bora da estrela. Na obra de Clarice Lispector, a questão do estrangeiro apresenta muitas faces, como se pode constatar em Clarice: uma vida que se conta (1995), de Nádia Battella Gotlib e em Linguas de fogo: ensaio sobre Clarice Lispector (2002), de Claire Varin.

A ensaísta brasileira, no texto mencionado, escreve uma biografia de Clarice Lispector, de forma bastante criativa, 
utilizando-se de imagens, de entrevistas e de reportagens. Ao mostrar uma intrínseca relação entre a vida e obra, evidencia as mediações entre a ficção e o real, acenando para o leitor de seu estudo crítico que a obra de Clarice não se constitui como um mero reflexo de dados biográficos. Nesse trabalho de reconstrução "de uma vida que se conta", o leitor acompanha a trajetória da família de Clarice para o Brasil, sua origem ucraniana, sua formação no "Grupo Escolar João Barbalho" e no "Colégio Hebreu-Ídiche-Brasileiro".

Em uma das partes de seu livro, comentando a transfiguração metafórica do dado biográfico, Nadia Battella Gotlib diz:

Mas a cultura hebraica, transfigurada metaforicamente, há de se manifestar na sua obra futura entre outras transfigurações, sob a forma de grito de rebeldia, denunciando a fome e a impotência da personagem, ela também prisioneira, como os macabeus, mas que, como eles, resiste, nordestina na cidade grande, massacrada por um sistema social desumano: Macabéa. (GOTLIB, 1995: 66)

O livro de Claire Varin, lançado no Canadá em 1990 e traduzido no Brasil em 2002 por Lúcia Peixoto Cherem, estabelece um diálogo bem próximo entre a biografia e a ficção de Clarice, escolhendo o caminho da "crítica transmudada em criação" (p. 23). Nesse sentido, a questão do estranhamento e do estrangeiro, relacionado ao âmbito biográfico, aparece em várias passagens do estudo crítico da ensaísta canadense. $\mathrm{Na}$ parte intitulada "O dom das línguas", em "A barata", a ensaísta afirma: "Clarice Lispector nasce sob o signo da vagueza, e também sob o da culpa (VARIN, 2002. 41). Esse aspecto aí evidenciado se desdobra em outros como: o enfoque sobre a questão lingüística vivenciada por Clarice 
em decorrência de sua origem judaica. Veja-se, a propósito, a parte intitulada "A estrangeira". ${ }^{2}$

A tensão entre biografia e ficção, com base no relacionamento vida / obra e migração / estranho / estranhamento / estrangeiro abre um campo amplo e fecundo para a compreensão da escritora brasileira. No entanto, o enfoque desse aspecto exigiria outras reflexões que ultrapassam o propósito desse estudo, embora reconheça a importância do biográfico para a elucidação da obra dos autores, tendo em vista sobretudo as novas tendências críticas no trato com o biográfico, conforme demonstram Nádia Battella Gotlib e Claire Varin.

Nesse sentido, penso na escrita de $A$ bora da Estrela, no momento em que a obra é recebida pelo público, sem que se considere a mediação vida e obra. Macabéa é, sem dúvida, a estrangeira no espaço urbano. Como tal impõe várias indagações disseminadas por todo livro. Assim, como não atentar para a condição da estrangeira Macabéa feita de "matéria parca e singela demais" ? (p. 19); na aventura estranha de "uma moça numa cidade toda feita contra ela" (p. 19); na "fotografia muda" (p. 21); na marginalização social de Macabéa? (p. 24); na ilogicidade de sua existência? (p. 26); na condição mutante do narrador/autor "que faz malabarismo de entonação e abriga o respirar alheio"? (p.29), 29); na eleição do sussurro em detrimento do fato? (p. 31); na Macabéa associada a um "café frio" (p. 34); na mudez de Macabéa (p. 37); na infância de Macabéa sem bola nem boneca? (p. 41); no grito de horror à vida? (p. 41); na ausência de presentes (p. 49); no gosto por parafuso e prego (p. 54) na atenção de Macabéa em relação às coisas insignificantes como ela própria (p. 63); no estranhamento em relação à própria língua (p. 67); na Macabéa gerada pela idéia vaga

${ }^{2}$ VARIN, 2000, p. 57-60. 
qualquer dos pais famintos (p. 70); na Macabéa, "cabelo na sopa"; na Macabéa, rebotalho social (p. 81); na Macabéa sertaneja paciente (p. 79); na Macabéa, a caixinha de música muito desafinada (p. 103) e na Macabéa estrela?

$O$ estranho e o estranhamento aparecem tanto nos textos de Monique Proulx como naqueles de Clarice Lispector. Tratar dessa questão é abrir muitos mapas de leitura. É compreender como o tão familiar pode-se tonar estrangeiro. Apesar da diferença entre os contextos históricos e culturais, o "mal estar" ultrapassa as fronteiras nacionais, pois decorre de situações do quotidiano no espaço urbano seja brasileiro ou canadense.

A produção literária de Clarice Lispector ocorre entre os anos 40 e 70 , sendo que o livro $A$ bora da estrela foi publicado em 1977. Monique Proulx, vivendo sob o signo do multiculturalismo no Canadá, em Les aurores montréales, abriga a questão da migração, especialmente a literatura migrante, instaurando pelos contos-cartas, dedicados aos escritores da literatura migrante (Yin Chen, Marco Micone e Dany Laferrière), um diálogo com essa tradição que já foi incorporada à história da literatura do Québec. ${ }^{3}$

Monique Proulx homenageia esses autores da literatura migrante, mantendo sempre essa tensão do "eu" em relação ao "outro", pois esse "eu" narrador, escrevente e migrante está inserido no texto de uma autora quebequense. No Canadá, Monique Proulx vive, historicamente, uma encruzilhada de culturas e de línguas que aparece em sua ficção. Clarice Lispector resgata o estrangeiro ou a estrangeira nordestina em seu próprio país, combinando, de forma paradoxal, estranha, a Macabéa-rebotalho social e a Macabéa-sertaneja com a Macabéaestrela.

${ }^{3}$ Cf. HEINZ et CHAMBERLAND (Org.), 1996, p. 278. 
O estranho, o estranhamento e o estrangeiro estão imersos no cotidiano, entrelaçados à maneira como os indivíduos se representam, se olham e, igualmente, são representados. No âmbito dos estudos contemporâneos, o tema, aqui tratado, passa a ser cada vez mais abordado, considerando o estudo das identidades e da desterritorialização que "en general, es una de las fuerzas centrales del mundo moderno porque traslada a la población trabajadora de unos países hacia los sectores y espacios reservados para las clases bajas en las sociedades relativamente adineradas." Acrescente-se a esse comentário, a questão do exílio presente na história da cultura e da política.

Résumé: Ce texte aborde l'étrange, l'étrangeté et l'étranger a partir des quelques nouvelles de la littérature du Québec (Les aurores montréales, de Monique Proulx) et d'autres récits, de Clarice Lispector. Pour développer le thème, les aspects suivants seront privilegies: l'isolement féminin et la découverte du "moi"; l'enfance, l'adolescence et l'expérience de l'étrangeté et, finalement, le regard de l'étranger et le sentiment d'être étranger/étrangère.

\section{Referências bibliográficas}

APPADURAI, Arjun. Dislocación y diferencia en la economía cultural global. In: APPADURAI, Arjun. La modernidad desbordada: dimensiones culturales de la globalización. Montevideo/Buenos Aires: Trilce/Fondo de la Cultura Económica de Argentina, 2001.

CUSSON, Marie. La mise en jeu de la ville dans Les aurores montréales de Monique Proulx. Globe: Revue Internacionale d'Études Québécoises. Montréal: Université de Québec, v. 5, n. 1, p.75-88, 2002.

FREUD, Sigmund. Uma neurose infantil e outros trabalbos. Trad. Jayme Salomão. Rio de Janeiro: Imago, 1969. v. 17. 
GOTLIB, Nádia. Teoria do conto. São Paulo: Ática, 1985.

GOTLIB, Nádia. Clarice: uma vida que se conta. São Paulo: Ática, 1995.

GUIMARÃES, Lívia Cristina. Estrangeiro de mim. Viagens, viajantes e suas estranhas identidades. 1997. Dissertação (Mestrado em Teoria da Literatura) - Faculdade de Letras da UFMG, Belo Horizonte.

HEINZ, Wienmann; CHAMBERLAND, Roger (Org.). Littérature québécoise, Des origines à nos jours. Textes et méthodes. Montréal: Éditions Hurtubise HMH, 1996.

KRISTEVA, Julia. Tocata e fuga para o estrangeiro. In: KRISTEVA, Julia. Estrangeiros para nós mesmos. Trad. Maria Carlota Carvalho Gomes. Rio de Janeiro: Rocco, 1994. p. 9-46.

LISPECTOR, Clarice. Laços de familia. 6. ed. José Olympio: Rio de Janeiro, 1974.

LISPECTOR, Clarice, A bora da estrela. 5. ed. Rio de Janeiro: José Olympio, 1979.

LISPECTOR, Clarice. Perto do coração selvagem. 7. ed. Rio de Janeiro: Nova Fronteira, 1980.

LISPECTOR, Clarice. Legiāo estrangeira. 3. ed. São Paulo: Ática, 1982.

PROULX, Monique. Les aurores montréales: nouvelles. Québec: Montréal, 1999.

ROLLEMBERG, Denise. Exillio: entre raízes e radares. Rio de Janeiro/São Paulo: Record, 1999.

VARIN, Claire. Linguas de fogo. Ensaio sobre Clarice Lispector. Trad. Lúcia Peixoto Cherem. São Paulo: Limiar, 2002 